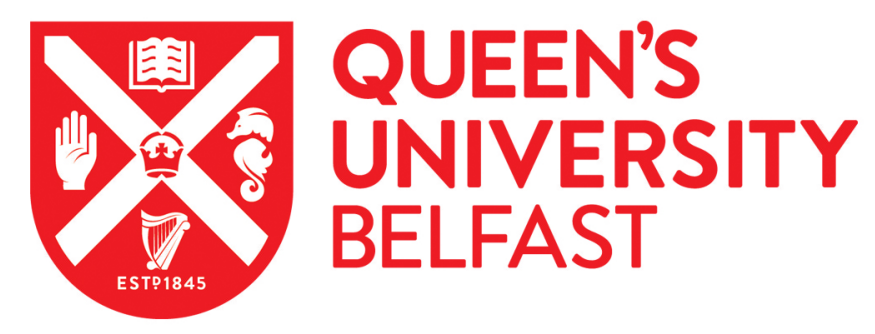

\title{
Patterns of alcohol consumption and cardiovascular risk in northern ireland and france.
}

Evans, A., Marques-Vidal, P., Ducimetiere, P., Montaye, M., Arveiler, D., Bingham, A., Ruidavets, J-B., Amouyel, P., Hass, B., Yarnell, J., Ferrieres, J., Fumeron, F., Luc, G., Kee, F., \& Cambien, F. (2007). Patterns of alcohol consumption and cardiovascular risk in northern ireland and france. Annals of Epidemiology, 17(5 SUPPL.), 7580. https://doi.org/10.1016/j.annepidem.2007.01.017

Published in:

Annals of Epidemiology

Queen's University Belfast - Research Portal:

Link to publication record in Queen's University Belfast Research Portal

\section{General rights}

Copyright for the publications made accessible via the Queen's University Belfast Research Portal is retained by the author(s) and / or other copyright owners and it is a condition of accessing these publications that users recognise and abide by the legal requirements associated with these rights.

Take down policy

The Research Portal is Queen's institutional repository that provides access to Queen's research output. Every effort has been made to ensure that content in the Research Portal does not infringe any person's rights, or applicable UK laws. If you discover content in the Research Portal that you believe breaches copyright or violates any law, please contact openaccess@qub.ac.uk. 


\title{
Patterns of Alcohol Consumption and Cardiovascular Risk in Northern Ireland and France
}

\author{
ALUN EVANS, MD, PEDRO MARQUES-VIDAL, MD, PhD, PIERRE DUCIMETIĖRE, PHD, \\ MICHELE MONTAYE, MD, DOMINIQUE ARVEILER, MD, ANNIE BINGHAM, MA, \\ JEAN-BERNARD RUIDAVETS, MD, PHILLIPE AMOUYEL, MD, PHD, \\ BERNADETTE HAAS, MD, JOHN YARNELL, MD, JEAN FERRIÈRES, MD, MSc, \\ FREDERIC FUMERON, PHD, GERALD LUC, MD, FRANK KEE, MD, \\ AND FRANCOIS CAMBIEN, MD
}

\begin{abstract}
The PRIME Study was begun in 1991 and recruited 10,600 men aged 50 to 59 years in the WHO MONICA Project centers of Belfast, Lille, Strasbourg and Toulouse. Although drinkers in France and Northern Ireland consumed almost identical amounts, the pattern of consumption was different. In Northern Ireland beer and spirits were the staple beverages, whereas in France it was predominantly red wine; in France, $90 \%$ of men drank at least one unit per week versus $61 \%$ in Northern Ireland. Frenchmen drank evenly throughout the week, whereas in Northern Ireland two thirds of the consumption took place on Friday and Saturday nights. In the 5-year follow up of PRIME in France, the usual cardiovascular protective effect of increasing consumption (up to 45 units per week) was shown and the level of significance for trend in consumption was highly significant $(p=0.006)$; in Northern Ireland, this pattern was less consistent and did not attain significance. It remains a matter of conjecture whether in Northern Ireland the beneficial effects of alcohol consumption were annulled by a pattern of drinking that increases blood pressure, a wellestablished risk factor for heart disease, or whether the protection in France resulted from the consumption of wine along with food.

Ann Epidemiol 2007;17:S75-S80. (c) 2007 Elsevier Inc. All rights reserved.
\end{abstract}

KEY WORDs: Alcohol Drinking, Cardiovascular Disease, Drinking Behavior.

\section{BACKGROUND}

In 1980, Ducimetière and his colleagues (1) drew comparisons between the Paris Prospective Study, the Seven Countries Study, and the Pooling Project. In France, coronary heart disease (CHD) death rates were distinctly lower than those in Northern and Eastern Europe and the United States. The authors reported that "numerous hypotheses have been proposed to explain the anomalous epidemiology of CHD in France-consumption of olive oil, of alcohol, especially wine, garlic, and so on." The authors quite properly continued: "The answers can only come from careful prospective study," and that "age, blood pressure and cholesterol levels are responsible for comparable risk gradients in France just as in other countries." They added that "not

From the PRIME Study Group (a complete listing of members and affiliations may be found at the end of the article).

The PRIME Study was funded by the Research and Development Office, a directorate of the Northern Ireland Health and Social Services Central Services Agency (RRG project 9.8), and the Merck, Sharpe and DohmeChibret Laboratory under an agreement between INSERM and participating laboratories (see end of article for the list of laboratories). measured or not yet identified variables contribute to the risk of CHD among American men.”

The following year, three of these authors coined the term "The French Paradox" after comparing levels of heart disease with fat intake data provided by the Organisation for Economic Cooperation and Development (OECD) (2). Consumption of animal fat in France was high despite the fact that CHD mortality data showed low age-standardized rates for males (35-64 years of age), lying just above Greece and Japan.

Different diagnostic practices in France had been invoked as a cause for the paradox. The World Health Organization's (WHO) MONICA Project was set up to evaluate the contribution of major risk factor change to diverse trends in $\mathrm{CHD}$ and stroke incidence around the world (3). MONICA rankings, based on MONICA categories of fatal events, placed some middle- and low-mortality populations, such as the French, higher than they would be based on official CHD mortality rates. However, rates for non-fatal myocardial infarction correlated quite well with the official mortality for the same populations. Moreover, when ranked by event rates for certain MONICA definitions, French MONICA populations had low rates that were comparable 
Selected Abbreviations and Acronyms

$\mathrm{CETP}=$ cholesterol ester transfer protein

$\mathrm{CHD}=$ coronary heart disease

ECTIM = Etude Cas-Temoins de l'Infarctus du Myocarde

$\mathrm{HDL}=$ high-density lipoprotein

MONICA = Multinational monitoring of trends and determinants in cardiovascular disease

MORGAM = MONICA, Risk, Genetics, Archiving, and Monograph OECD $=$ Organisation for Economic Cooperation and Development PRIME $=$ Prospective Epidemiological Study of Myocardial Infarction WHO $=$ World Health Organization

with those in other European populations in Italy, southern Germany, Switzerland. and Spain.

In a dietary comparison of Belfast and Toulouse mounted within the MONICA Project (4), alcohol consumption in Toulouse was significantly higher than in Belfast: the Toulousains drink red wine, rather than beer and spirits, and drink daily; in Belfast fewer people drink but those who do make up for it, particularly in binge drinking at weekends. Large studies have now shown a reduced relative risk for CHD in moderate drinkers. It is suggested that a steady consumption of wine in France reduces platelet aggregation (5) and that binge drinking induces rebound aggregation.

The Étude Cas-Tèmoins de l'Infarctus du Myocarde (ECTIM) Study is a large case-control study of myocardial infarction mounted between the MONICA centers in Belfast, Lille, Strasbourg, and Toulouse, for which male patients 25 to 64 years of age were recruited (6). Despite an almost four-fold higher level of heart disease in Northern Ireland than in France, classical risk factor levels were very similar. After adjusting for classic risk factors and country of recruitment by logistic regression, alcohol displayed a protective effect against myocardial infarction (7). The magnitude of the effect, which was comparable in the two countries, was related to wine consumption in France and beer and spirits consumption in Northern Ireland. This effect largely disappeared when high-density lipoprotein (HDL) cholesterol was included in the model. Among 605 controls in ECTIM, of a host of lipid and hemostatic factors investigated, only HDL parameters and plasminogen activator inhibitor 1 activity were increased by alcohol consumption (8).

In a later work from the ECTIM Study, an important gene-environment interaction between alcohol consumption and a polymorphism of the cholesterol ester transfer protein (CETP) gene (CETP/Taq1B) was observed (9). CETP cycles HDL cholesterol to the low-density lipoprotein cholesterol pool, and reduced levels of enzyme will lead to higher levels of HDL cholesterol. The gene has two alleles, B1 (60\%) and B2 (40\%), and B2 carriers had highly significantly lower levels of CETP and higher levels of HDL cholesterol. The effect on plasma HDL cholesterol was not observed in B2 carriers drinking less than $25 \mathrm{~g}$ of alcohol per day but increased commensurately with greater intakes. The odds ratios for myocardial infarction in $\mathrm{B} 2$ homozygotes decreased from 1.0 in nondrinkers to 0.34 in those drinking $75 \mathrm{~g} / \mathrm{d}$ or more. Similar but weaker effects were also present for the B1 allele.

On the strength of the results from the ECTIM Study, it was decided to mount a prospective study, the Prospective Epidemiological Study of Myocardial Infarction (PRIME) (10), whose methods are outlined below.

\section{Methods}

The PRIME study recruited 10,600 men aged 50 to 59 years from the populations of the WHO MONICA Centres of Belfast, Northern Ireland, and Lille, Strasbourg and Toulouse in France from 1991 through 1993, assembling roughly equal cohorts in each center. The basic procedures have been described (11) but, briefly, the standard questionnaire also gathered information on medical history, chest pain, physical activity, and tobacco and alcohol consumption. Participants were informed of the aims of the study, and those who agreed to take part signed a consent form. Ethical clearance was obtained from the appropriate local Research Ethics Committees.

Alcohol consumption was assessed by means of a validated questionnaire that recorded the subjects' mean consumption (in units) of wine, beer, cider, and spirits for each day of the week. The intake of alcohol (expressed in milliliters of pure ethanol/week) was estimated from the average number of milliliters of ethanol in one unit of each type of alcoholic beverage (11). Subjects were considered former drinkers if they reported no current alcohol consumption but indicated that they had consumed alcohol in the past (for any period of time).

Blood pressure was measured once at the end of the examination after a 5 -minute rest in the sitting position. Measurements were performed with an automatic device (Spengler SP9), which also recorded heart rate (12).

\section{Follow up for CHD events over 5 years}

Subjects were contacted annually by postal questionnaire, by telephone, or through their family doctors. Possible events were followed up through the hospital or the family doctor. All death certificates were recorded and the circumstances ascertained; loss at follow-up amounted to $0.8 \%$ in Belfast and $1.4 \%$ in France. A medical committee independently validated the coronary events with information gathered from all medical sources. Myocardial infarction and definite coronary deaths were defined according to MONICA criteria. "Hard" CHD cases were defined as coronary deaths or nonfatal myocardial infarction (13). The criteria also allowed for the classification of cases of angina, differentiating stable and unstable angina. 


\section{Results of new analyses}

Although drinkers in France and Northern Ireland consumed almost identical amounts, the pattern of consumption was entirely different (13). Mean intake, expressed in milliliters of alcohol per week, was slightly higher in Northern Ireland than in France (mean \pm standard deviation: $326 \pm 333$ vs. $318 \pm 249 \mathrm{~mL} /$ wk; Kruskal-Wallis $=8.20$, $p=0.01)$. In Northern Ireland, beer and spirits were the staple beverages, whereas in France it was predominantly red wine. In France, 90\% of men drank at least one unit of alcohol per week; the proportion in Northern Ireland was $61 \%$. In addition, while the French cohort drank more or less evenly throughout the week, in Northern Ireland two thirds of the consumption took place on Friday and Saturday nights. In both countries, current smokers had higher consumption of all types of alcoholic beverages than nonsmokers. In Northern Ireland, subjects who reported some physical activity consumed significantly less alcohol than sedentary subjects, whereas higher consumption was associated with dyslipidemia in France. In France total alcoholic intake, irrespective of type, was inversely associated with socioeconomic status and educational level. The same was true for total intake in Northern Ireland, although red wine was positively associated with higher socioeconomic and educational status.

The weekly patterns of alcohol consumption were investigated. In this analysis, those drinking at least one unit of alcohol per week amounted to 5663 and 1367 in France and Northern Ireland, respectively. (Some subjects were excluded from the study: 593 because of preexisting CHD, 1825 because of antihypertensive or cholesterol-lowering treatment, and an additional 207 subjects in France who were screened on a Saturday.) After adjustment for age, body mass index, heart rate, tobacco smoking, educational level, marital status and professional activity, it was found that blood pressure was higher in Northern Irish drinkers screened on Mondays and Tuesdays and decreased until Thursday (14). In French drinkers, blood pressure levels were constant throughout the week (day by country interactions, $p<0.05$ ). In both countries, drinkers had higher blood pressure levels than non-drinkers. Data from the Belfast MONICA Register for 1991-1993 for fatal definite and possible myocardial infarction indicated a higher prevalence of events on Mondays and Tuesdays and a lower incidence on Fridays $(p=0.05)$ in both sexes.

A total of 9750 subjects, free of CHD at baseline, were included in the analyses of the 5-year follow up: 7532 in France and 2398 in Northern Ireland. There were 106 coronary deaths or myocardial infarctions and 94 angina pectoris events in France; the corresponding events in Northern Ireland were 61 and 60. A combined classification into "CHD events" (angina pectoris, myocardial infarction, or coronary death) (12) yielded 197 events (2.7\%) in France and 121 (5.0\%) in Northern Ireland. In France, after adjusting for other CHD risk factors, subjects in the highest quartile of alcohol consumption had a significantly lower risk of developing angina pectoris in comparison with nondrinkers. For myocardial infarction and all CHD events, the risk also decreased from the first to the fourth quartile ( $p$ for trend $=$ 0.02). Conversely, in Northern Ireland, no significant relationship was found between alcohol consumption and the development of angina pectoris or all CHD events, although alcohol consumption appeared to reduce the risk of myocardial infarction. There was a suggestion that wine intake had a protective effect in Northern Ireland (Fig. 1). Excluding subjects on sick leave or with possible alcohol-related

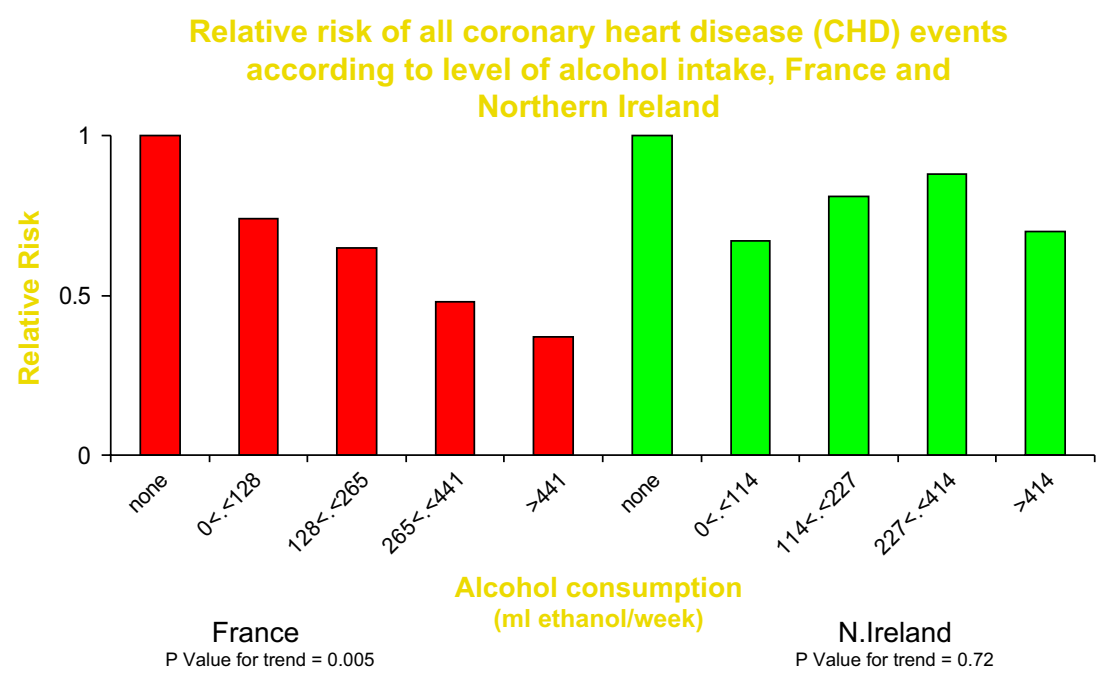

FIGURE 1. Relative risk of all coronary heart disease (CHD) events accordingto level of alcohol intake, France and Northern Ireland. 


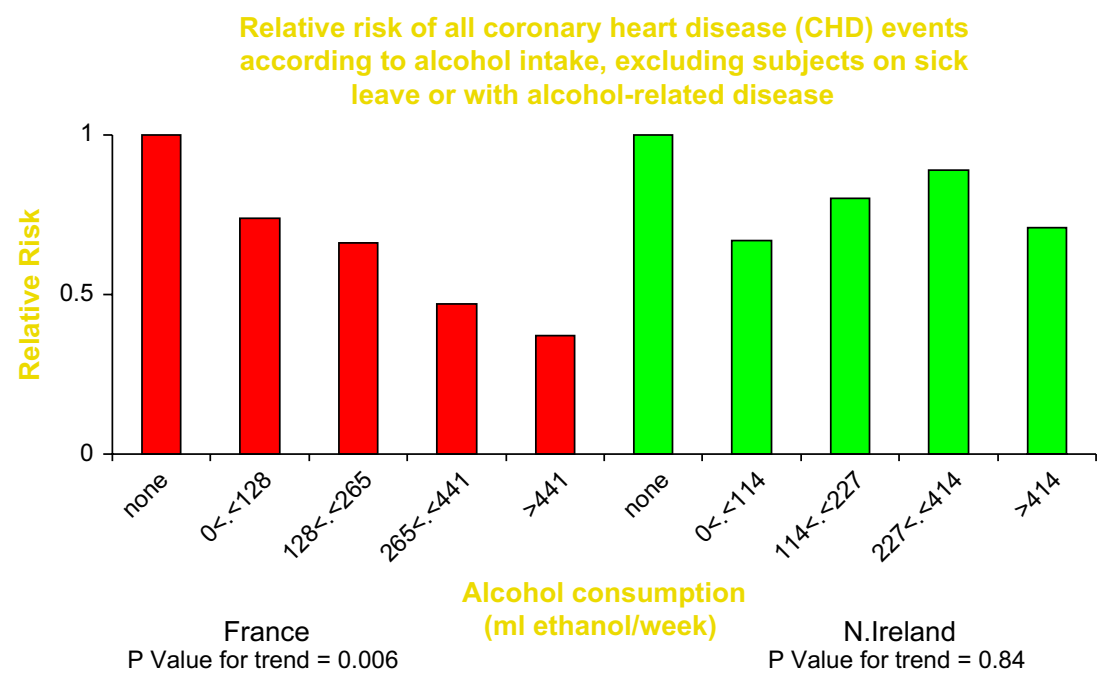

FIGURE 2. Relative risk of all coronary heart disease (CHD) events according to alcohol intake, excluding subjects on sick leave or with alcohol-related disease.

diseases from the non-drinker group, removing the bias of former drinking ("sick quitters"), made no difference to the results (Fig. 2).

\section{DISCUSSION}

In the PRIME study we have observed profound differences in the pattern of consumption, the type of consumption and the amount consumed at one time, and the degree of cardioprotection afforded. The PRIME finding of higher blood pressure in men screened on Mondays and Tuesdays (14) confirms a similar finding from the British Regional Heart Study in 1991 (15), which did not extend to Northern Ireland. The crucial point is that these effects were absent in France where the pattern of drinking is different. Could the effect observed in Northern Ireland have been due to bias? There is a famous example of how disease detection can vary as a result of selective participation. In the Medical Research Council's study of miners in South Wales in the early 1950s, cases of pneumoconiosis were picked up on $\mathrm{x}$ ray early in the survey, whereas cases of tuberculosis were detected at the end (16). The miners had been left to select when they were screened, and those with pneumoconiosis came early as they had fair insight into their condition and were eligible for compensation, whereas those with tuberculosis came late; they suspected they had a disease which bore stigma and which was ineligible for compensation. Could such factors have been operating in Northern Ireland? Were subjects with raised blood pressure appearing early in the week because they wanted it checked? In PRIME the men were randomly allocated their day of screening and no differences in several characteristics of the men screened on different days were detected. Therefore, we have to accept the effect as real and it helps to explain the observation that heart attacks are most common in Northern Ireland on Mondays and least common on Fridays.

There are a number of plausible mechanisms for these effects: acute alcohol consumption modulates intracellular sodium and decreases adrenoreceptor-mediated cardiovascular reactivity; smoking cigarettes while drinking may increase fibrinogen; salted foods consumed while drinking may raise blood pressure; or the large water load from beer consumed may lead to a secondary hyperaldosteronism. The apparent lack of a cardioprotective effect from alcohol consumption in Northern Ireland in comparison to France is an important finding (11). Again, could bias have been operating? How much of the lack of protection could have been caused by under-reporting, or even over-reporting, because of guilt surrounding alcohol use (see below), or is it that those who drink a lot on two or three occasions a week simply cannot accurately recollect how much they have consumed? It is important to remember that in Northern Ireland only $61 \%$ of men drank (as opposed to 90\% in France); two thirds of their intake took place at weekends, yet they drank rather more per occasion than in France (13). French subjects consuming alcohol moderately would have a very shrewd idea of how much they consumed. Klatsky and his colleagues have estimated that the increased odds ratio for hypertension in persons reporting one to two drinks per day appears to be due, in part, to under-reporting (17).

Could the apparent lack of protection in Northern Ireland have been due to relatively small numbers of events? This question will have to await the imminent analyses of the 10-year follow-up that will approximately double the 
number of events. This will permit a fuller investigation of the effects of different patterns of alcohol consumption. Another question relates to the type of alcohol consumed. Naturally enough, men in France, where wine is produced, consume more wine than men in Northern Ireland. There was a suggestion in Northern Ireland that wine was protective, but the group deriving the apparent benefit was small and skewed toward higher socioeconomic status; this group enjoys better health status and, even after adjustment, residual confounding remains an issue. Wine may exert a protective effect because of the bioflavonoids (18) and estrogen mimickers (e.g., phytoestrogens) it contains (19).

Whether the beneficial effects of alcohol consumption in Northern Ireland were annulled by a pattern of drinking that increases blood pressure, a well-established risk factor for heart disease, or whether consumption of wine along with food gives further protection in France by increasing the absorption of bioflavonoids, is a matter for conjecture. However, to add a word of caution in interpreting these data, Ingster and Feinleib (20) have postulated that the increase in salicylates in food could account for the decline in cardiovascular mortality observed in the United States. Alcohol users notoriously dose themselves with salicylates and some of the "protection" could be due to this.

\section{DRINKING PATTERNS IN NORTHERN IRELAND}

These very different patterns of alcohol consumption are deep seated. How did the pattern in Northern Ireland become established? In his book The Classic Slum, Roberts (21) gives an account of social conditions in Salford, in Northern England around 1900. Roberts records that, "To the great mass of manuals the local public house spelled paradise." The caption to a photograph of men about to enter a bar reads, "The shortest way out of Manchester." He also states that many small business employers of labor paid out their weekly wages there, so the weekend would have got off to a bad start. The same system operated in Belfast with stevedores paying the dockers in the bar at the end of the week (Boyd A, Cassells J, letter/telephone communication, June 2006). This practice was common among Irish construction workers in London until recently; in addition, in the 19th century, Irish Navvies were often paid in beer (22). The payment of a weekly wage also helped to establish these patterns of drinking. Among the professional classes, being paid monthly may have induced a different pattern.

The tight grip of religion in Northern Ireland is undoubtedly also exerting an effect on these patterns of alcohol consumption. The Irish Nobel Laureate William Butler Yeats, a member of the Protestant Ascendancy, wrote of "the fascination of what's difficult," in relation to the Protestant Ethic, which may be translated as "hard working and abstemious, with a tendency to dourness." Protestant fundamentalists go to the intemperate lengths of "good-living," which means total abstinence, probably denying themselves some health benefits from drinking temperately. It should be appreciated, however, that these attitudes and habits exist on both sides of the religious divide, but there may be a lesser tolerance to alcohol abuse in Protestant families (23). Even in less extreme religious groups, the desire to obey the Commandment, "to keep the Sabbath day holy," combined with the strong work ethic that demands turning up sober and early for work on weekdays, serves to punctuate the drinking pattern and builds up a thirst for the weekend. Added to this, the guilt which surrounds alcohol consumption, no doubt fueled by religious beliefs, could be a cause of underreporting. It is an odd coincidence that the town with the biggest problem with hard drugs in Northern Ireland is situated in Ian Paisley's constituency. It seems that fundamentalist doctrines and religious certainties are comforting for some, but create a need for escapism in others. It may be the case that alcohol is commonly used as a vehicle for escape in Northern Ireland, whereas in France it is more une aide nourriture. Added to this may be the fact that in France a small intake of alcohol with food begins at an early age, whereas in Northern Ireland, in the past, at least, alcohol consumption began relatively late in life, almost exclusively without food, and then tended to be overdone. The focus on abstention prevents young people from learning to drink safely, as they are in more permissive alcohol cultures in southern Europe (24). It seems that the best advice on alcohol intake should be the same as that on how to feed a horse: "little and often." These crosscultural differences in alcohol intake will be assessed further in MORGAM (MONICA, Risk, Genetics, Archiving, and Monograph), a large European pooling project (25).

A protective effect of alcohol consumption against CHD in France was apparent despite the higher smoking and blood pressure levels associated with increasing levels of drinking, suggesting that the effect is strong. Moreover, the fact that a large majority of men are deriving a possible benefit from alcohol and that in Northern Ireland this effect is virtually absent, could go some way to explaining the "French Paradox." By 1992, Ducimetière and Richard (26) were asking, "Is there a French Paradox?" The authors believed that the different mortality experienced in France and in its neighboring countries could be much more readily explained by the specific alcohol drinking habits of its population than by any other dietary peculiarity. They also concluded, "The idea that the dietary lipid concept might represent the spine of CHD etiology, but not its whole body, has gained ground during the past 10 years and recognition of this proposition means that there is no place for 
any French Paradox." However, perhaps, like the "Legal Paradox," the "French Paradox" is one of those libels which "...may be the more a libel for being true (27)."

The PRIME Study Group and affiliated projects/institutions: Coordinating Center, INSERM U258, Paris-Villejuif, France (P.D., A.B.), Strasbourg MONICA Project, Department of Epidemiology and Public Health, Faculty of Medicine, Strasbourg, France (D.A., B.H.); Toulouse MONICA Project, INSERM U558, Department of Epidemiology, Paul SabatierToulouse Purpan University, Toulouse, France (J.F., J.B.R.); Lille MONICA Project, INSERM U508, Pasteur Institute, Lille, France (P.A., M.M.); Department of Epidemiology and Public Health, Queen's University, Belfast, Northern Ireland (A.E., J.Y., F.K.); Department of Atherosclerosis, INSERM UR545, Lille, France (G.L., J. M. Bard); Laboratory of Haematology, La Timone Hospital, Marseilles, France (I. JuhanVague); Laboratory of Endocrinology, INSERM U326, Toulouse, France (B. Perret); Vitamin Research Unit, University of Bern, Bern, Switzerland (K. F. Gey); Trace Element Laboratory, Department of Medicine, Queen's University Belfast, Northern Ireland (Jayne Woodside, Ian Young), Faculté de Médecine Pitie-Salpetriere, INSERM 525, France (Francois Cambien); Faculté de Médecine Xavier Bichat, INSERM U695, France (Frédéric Fumeron); Instituto de Medicina Molecular, Faculdade de Medicina, Universidade de Lisboa, Portugal (Pedro Marques-Vidal).

We thank the organizations which allowed the recruitment of the PRIME subjects : the health screening centers organized by the Social Security of Lille (Institut Pasteur), Strasbourg, Toulouse and Tourcoing; Occupational Medicine Services of Haute-Garonne, of the Urban Community of Strasbourg; the Association Inter-entreprises des Services Médicaux du Travail de Lille et environs; the Comité pour le Développement de la Médecine du Travail; the Mutuelle Générale des PTT du Bas-Rhin; the Laboratoire d'Analyses de l'Institut de Chimie Biologique de la Faculté de Médecine de Strasbourg; the Department of Health (NI) and the Northern Ireland Chest Heart and Stroke Association.

\section{REFERENCES}

1. Ducimetiere P, Richard JL, Cambien F, Rakotovao R, Claude JR. Coronary heart disease in middle-aged Frenchmen: Comparisons between Paris Prospective Study, Seven Countries Study and Pooling Project. Lancet. 1980;1:1346-1350.

2. Richard JL, Cambien F, Ducimetiere P. Particularités epidemiologiques de la maladie coronarienne en France. Nouv Presse Med. 1981;10:11111114 .

3. Tunstall-Pedoe H, Kuulasmaa K, Amouyel P, Arveiler D, Rajakangas AM, Pajak A. Myocardial infraction and coronary deaths in the World Health Organization MONICA Project: registration procedures, event rates, case fatality rates in 38 populations from 21 countries in 4 continents. Circulation. 1994;90:583-612.

4. Evans AE, Ruidavets JB, McCrum EE, Cambou JP, McClean R, DousteBlazy P, et al. Autres pays, autres coeurs? Dietary patterns, risk factors and ischaemic heart disease in Belfast and Toulouse. Q J Med. 1995;88:469-477.

5. Renaud S, de Logeril M. Wine, alcohol, platelets and the French Paradox for coronary heart disease. Lancet. 1992;339:1523-1526.

6. Parra HJ, Arveiler D, Evans AE, Cambou JP, Amouyel P, Bingham A, et al. A case-control of lipoprotein particles in two populations at contrasting risk for coronary heart disease: the ECTIM Study. Arterioscler Thromb. 1992;344:1315-1318.
7. Marques-Vidal P, Ducimetiere P, Evans A, Cambou J-P, Arveiler D. Alcohol consumption and myocardial infarction: a case-control study in France and Northern Ireland. Am J Epidemiol. 1996;143:1089-1093.

8. Marques-Vidal P, Cambou JP, Nicaud V, Luc G, Evans A, Arveiler D, et al. Cardiovascular risk factors and alcohol consumption in France and Northern Ireland. Atherosclerosis. 1995;115:225-232.

9. Fumeron F, Arveiler D, Evans AE. Alcohol intake modulates the effect of a polymorphism of the cholesterol ester transfer protein gene on high den sity lipoprotein and the risk of myocardial infarction. J Clin Invest. 1995;3:1664-1671.

10. Yarnell JWG. The PRIME Study: Classical risk factors do now explain the severalfold differences in risk of coronary heart disease between France and Northern Ireland. Q J Med. 1998;91:667-676.

11. Marques-Vidal P, Montaye M, Arveiler D, Evans A, Bingham A, Ruidavets J-B, et al. Alcohol consumption and cardiovascular disease: differen tial effects in France and Northern Ireland. The Prime Study. Eur J Cardiovasc Prev Rehabil. 2004;11:336-343.

12. Ducimetiere P, Ruidavets J-B, Montaye M, Haas B, Yarnell J. Five year incidence of angina pectoris and other forms of coronary heart disease in healthy men age 50-59 in France and Northern Ireland: the Prospective Epidemiological Study of Myocardial Infarction (PRIME) study. Int J Epidemiol. 2001;3:1057-1062.

13. Marques-Vidal P, Arveiler D, Evans A, Montaye M, Bingham A, Ruida vets JB, et al. Patterns of alcohol consumption in middle-aged men from France and Northern Ireland. The PRIME Study. Eur J Clin Nutr. 2000;54:321-328

14. Marques-Vidal P, Arveiler D, Evans A, Amouyel P, Ferriere J, Ducimetiere P. Different alcohol drinking and blood pressure relationships in France and Northern Ireland: The PRIME Study. Hypertension. 2001;38:13611366.

15. Wannamethee G, Sharper AG. Alcohol intake and variations in blood pressure by day of examination. J Hum Hypertens. 1991;5:59-67.

16. Cochrane AL. The detection of pulmonary tuberculosis in a community. Br Med Bull. 1954;10:91-95.

17. Klatsky AL, Gunderson EP, Harald K, Udaltsova N, Friedman GD. Highe prevalence of systematic hypertension among moderate alcohol drinkers: an exploration of the role of underreporting. J Stud Alcohol. 2006;67:421-428

18. Yarnell JWG, Evans AE. The Mediterranean diet revisited - towards resolving the (French) paradox. Q J Med. 2000;93:783-785.

19. Sans S, Evans AE. Are cardiovascular disease trends driven by gadflies? [letter] Int J Epidemiol. 2001;3:624-625.

20. Ingster LM, Feinleib M. Could salicylates in food have contributed to the decline in cardiovascular disease mortality? A new hypothesis. Am J Public Health. 1997;87:1554-1557.

21. Roberts R. The classic slum. Food, drink and physic. Manchester: Manchester University Press; 1971.

22. Cowley U. The men who built Britain: A history of the Irish navy. Dublin: Wolfhound Press; 2004.

23. Walls P. The health of Irish descended Catholics in Glasgow: A qualitative study of the links between health risk and religious and ethnic identities. PhD thesis. Glasgow: University of Glasgow, 1996.

24. Tilki M. The social contexts of drinking among Irish men in London. Drug Educ Prev Pol. 2006;13:247-261.

25. Evans A, Salomaa V, Kulathinal S, Asplund K, Cambien F, Ferrario M, et al. MORGAM (an international pooling of cardiovascular cohorts). Int J Epidemiol. 2005;34:21-27.

26. Ducimetiere P, Richard JL. Dietary lipids and coronary heart disease: is there a French Paradox? Nutr Metab Cardiovasc Dis. 1992;2:195-201.

27. The Shorter Oxford English Dictionary. Oxford (UK): Oxford University Press; 1964:1428. 